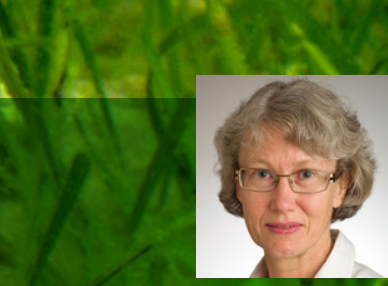

Dr Ingrid Ahnesjö

Dr Ines Braga Goncalves Malin Nygård

E: ines.goncalves@bristol.ac.uk T: +447876544619 W: https://www.researchgate.net/profile/Ines_Goncalves3 W: https://sites.google.com/site/kvarnemolab/home W: https://katalog.uu.se/profile/?id=XX3262

\title{
Pipefish male pregnancy: Why do females prefer large mates?
}

\section{Research Objectives}

Ines Braga Goncalves is a behavioural ecologist with broad interests in animal behaviour, communication and physiology.

\section{Detail}

University of Bristol

School of Biological Sciences

Life Sciences Building

24 Tyndall Avenue

BS8 1TQ Bristol, UK

\section{Bio}

Charlotta Kvarnemo and Ingrid Ahnesjö were Ines Braga Goncalves' PhD supervisors (2006-2010) and they have been working together ever since. They really enjoy working together and their scientific strengths complement each other; they are also good friends. This provided them the opportunity to co-supervise the Masters thesis of Malin Nygård.

\section{Funding}

Vetenskapsrådet, Svenska forskninsgrådet Formas, Inez Johansson Foundation and Uppsala University.

\section{Collaborators}

Malin Nygård, Charlotta Kvarnemo and Ingrid Ahnesjö.

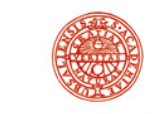

UPPSALA UNIVERSITET
䜿遂 University of (2) BRISTOL

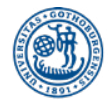

UNIVERSITY OF GOTHENBURG

\section{References}

- Nygård M., Kvarnemo C., Ahnesjö I. \& Braga Goncalves I. (2019) Pipefish embryo oxygenation, survival, and development: egg size, male size, and temperature effects. Behavioral Ecology, 30 (5), 1451-1460. doi:10.1093/beheco/arz101

- Braga Goncalves I. Kvarnemo C., Ahnesjö I. (2015). Embryo oxygenation in pipefish brood pouches: novel insights. Journal of Experimental Biology. 218, 16391646 doi:10.1242/jeb.120907

\section{Personal Response}

\section{Please describe some feature of the pipefish lifestyle} that you find especially intriguing or charming.

II Pipefishes are enchanting and still very much mysterious creatures. The broad-nosed pipefish, in particular, has inspired decades of dedicated research by multiple generations of biologists and we hope it will continue to do so for many years to come. How do they select which bay to breed in when they emerge from deeper water in early spring? What factors determine the yearly changes we observe in population densities? How will they cope and/or adapt to climatic changes that affect not only themselves, but also their food, their predators, their parasites and pathogens, and their habitat at large? How will all these factors affect their mating system and reproductive biology? The questions are literally endless. 
Biology | Ines Braga Goncalves

\section{Pipefish male pregnancy}

Why do females prefer large mates?

Parental care is an important factor to reproductive success, and studies of care quality can help in understanding mate choice and other reproductive decisions. In the become 'pregnant' and care for their embryos until birth Large and small male pipefish adopt different parental care strategies, and females favour larger mates. Researcher Ines Braga Goncalves at the University of Bristol's School close colleagues Malin Nygård and Charlta Kvarnemoatrd the University of Gothenburg together with Ingrid Ahnesjö at Uppsala University, study pipefish pregnancy to discover why females prefer larger

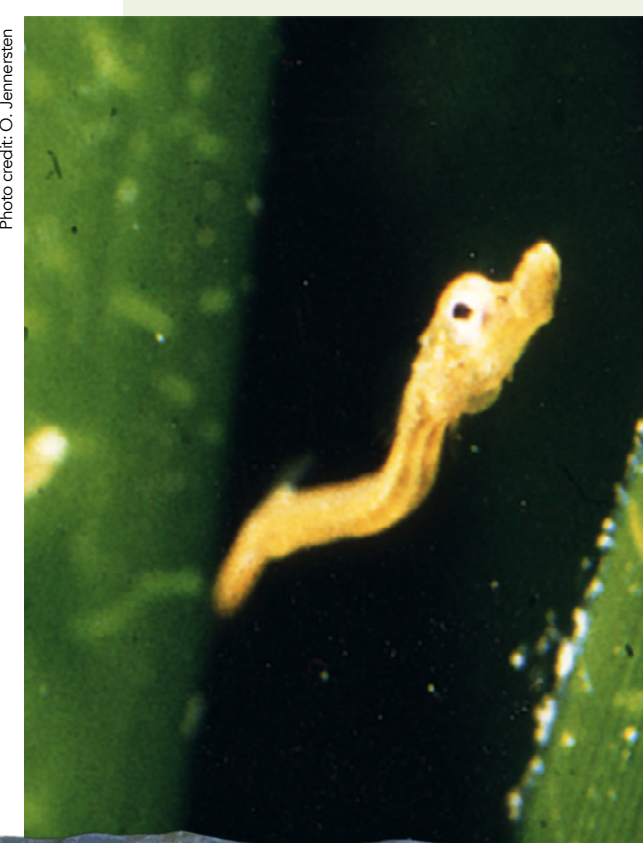

n fish, parental care, where it occurs, is most often provided by males. Males of pipefishes, seahorses and seadragons (family Syngnathidae) care for developing through to birth. In genera with bro pouches, such as Syngnathus, the care provided has similarities with mammalia pregnancy, so brooding males are said to be 'pregnant'.

Parental care enhances the survival and quality of offspring of many different costs for the parent providing it, and affects reproductive success over its lifetime. When parental resources are limited, a trade-off between number and size of offspring can result in brood reduction but at what cost or advantage?

In broad-nosed pipefish, a temperate sealiving species from the Eastern Atlantic Ocean, males have two skin folds that form a pouch into which females deposit eggs when mating. After mating, males protect the embryos, and provide oxygen and nutrition (in addition to the yolk that he juveniles emerge from the pouch.

Study results described here suggest that in the broad-nosed pipefish, Syngnathus typhle L. 1758, there is a the embryo density (embryo number divided by volume of the brood pouch) that males can care for; males favour one or the other option, depending on their own body size. Despite having differen parental strategies, small and large males incur similar losses in body condition during pregnancy.

EGG SIZE VERSUS EGG NUMBER IN A PIPEFISH BROOD POUCH In fish, larger eggs usually give
larger embryos and juveniles that grow faster and survive better. Egg size is positively correlated with female body size in the broad-nosed pipefish and each female produces eggs of similar size. When mated with small males compared to large males, temales compensate by cransfering eggs with higher protein (n) heir eggs.

Developing fish offspring need oxygen, which has lower diffusion and solubility in water compared with air. Embryos respire through the egg's surface. It is intuitive to expect that the surface-area-to-volume ratio (size) of large eggs is unfavourable. However, large eggs seem to do just as well as (or better than) small eggs, even under limited oxygen availability. volume ratio (size) of eggs does not affect respiration as much as previously thought.

Collaborators Ines Braga Goncalves at the University of Bristol, Malin Nygård and Charlotta Kvarnemo at the University of Gothenburg, and Ingrid Ahnes at Upssala University study pipefish pregnancy to understand why females set out to investigate if ege size team oxygen saturation levels in the pouch and if pouch oxygen saturation level differed between differently sized males. Approximately one-third of the way through male pregnancy (18 days) they measured oxygen saturation levels, egg density in the pouch, embryo mass, embryo survival and male body condition.

Bigger males have longer and wider brood pouches that can fit more eggs yet still offer a less dense brooding Lowironment for developing embryos. Lower embryo densities in the pouch could improve nutrient and oxygen
provisioning to the offspring. Large males provisioning to the offsping. Large males were found to produce heavier embryos, males brooded more densely packed lower embryo mass.

Studies by other researchers on broadnosed pipefish have found that females prefer larger partners. After birth, larger uveniles grow faster and sunvive better. It appears that large male pipefish are preferred partners because they positively affect offspring body size at 'birth' and do so independently of initial size of the eggs provided by the female.

\section{PROVIDING OXYGEN TO} DEVELOPING EMBRYOS IN THE BROOD POUCH Brooding males provide an oxygenated pouch environment for developing to bic probes were used theasure oxygen saturation levels in development. The oxygen levels in the pouches were lower than in the surrounding sea water and decreased as embryos developed.

Levels of oxygen inside the pouch were higher in the bottom than the middle section, especially in large males. This could be due to lower local embryo density and closer contact with the vascularised pouch walls. If lower egg densities overall result in higher pouch oxygen levels, large males would be able to provide a more oxygenated environment for embryos than do smaller
males. But this was not found.

Oxygen saturation levels in the brood pouch This could arise if: large and small eggs consume similar amounts of oxygen during initial development; males provide the same oxygen environment whatever their size; the varying oxygen demands of developing embryos result in the same oxygen levels overall.

Brooding males transfer nutrients to developing embryos and can absorb nutrients from lost eggs or embryos in the pouch. Perhaps large males supply more nutrients per embryo because of the lower egg density in their brood pouch Their embryos might also be heavier f nutrients are reallocated from lost
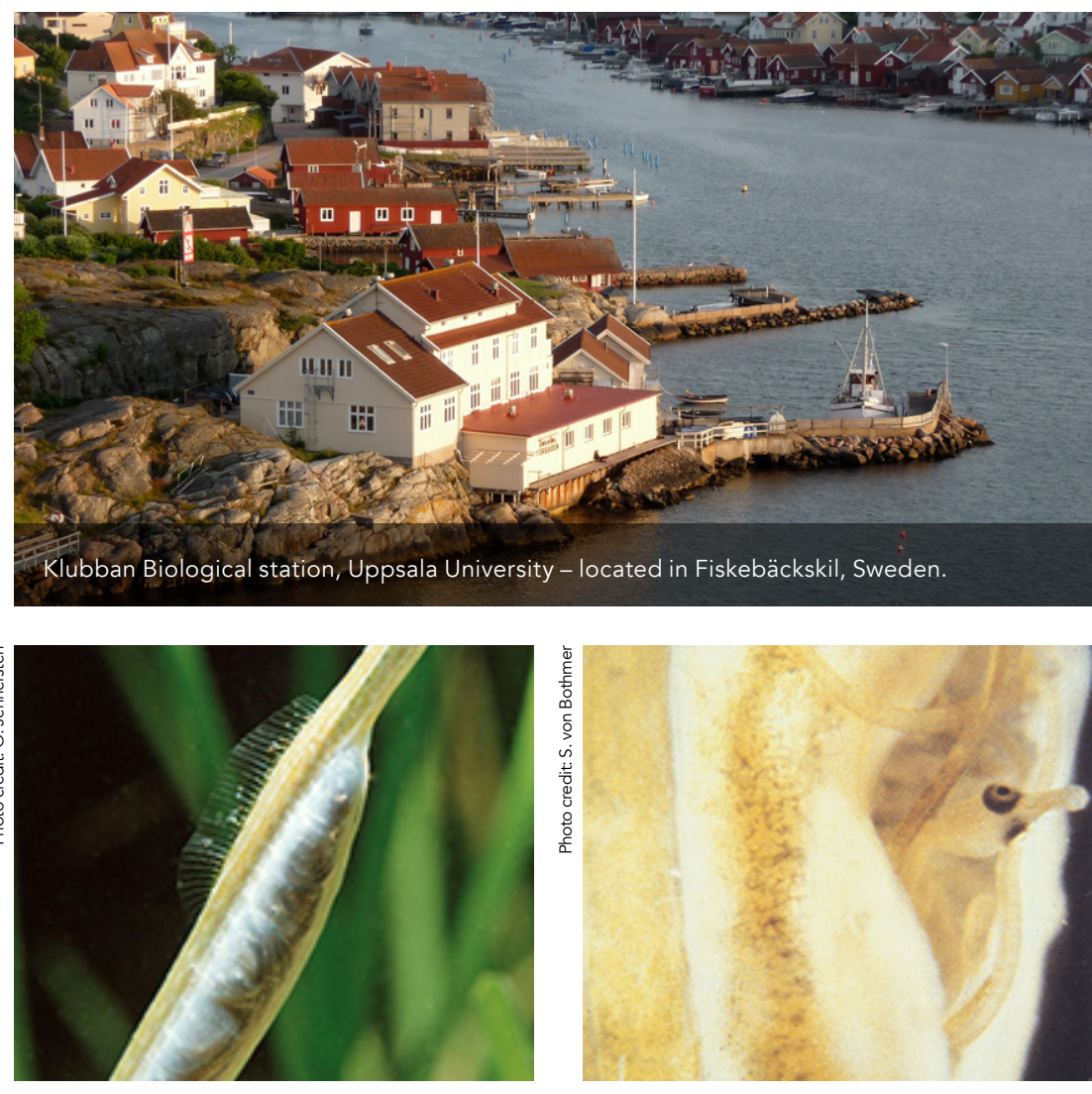

Egg size had no effect on embryo survival
pouch oxygen saturation.

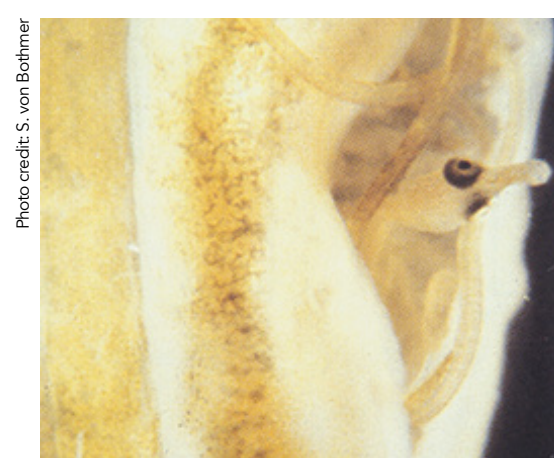

Larger offspring have better chances of surviva
once outside the protection of the pouch.

Large malles were found to produce heavier embryos, independent of initial

egg size. Small males brooded more densely packed embryos that had

better survival but lower embryo mass.

\section{EFFECTS OF WATER}

\section{TEMPERATURE ON BROODING}

The research team found that males that

lower pouch oxygen saturation levels than

males that brooded in cooler conditions. In other fish studies, water temperature has been found to adversely affect the amount of oxygen dissolved in the water but to increase fish metabolism, embryo developmental rates and, therefor, embryo oxygen consumption.

If water temperature affected food intake and feeding activity of broad-nosed pipetish in similar ways to that seen in other fish species, this could explain the more modest decrease in condition in males that brooded in warmer water, respic thic predicted faster mabolic condition did not differ between the (a) would emperatures have higher average food intake.

Egg size seems to matter less than expected in the broad-nosed pipefish in that it had no effect on embryo survival or pouch oxygen saturation. The overall esults suggest that, for the female broadnosed pipefish, choosing a larger male, who is likely to produce larger juvenlies, sef the pouch Though the protection of the pouch. Though small males may have their offspring are smaller, with pregnar energy resenves, and may then fit into more mouths that want to eat the 


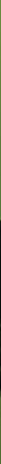

The public outreach magazine for the research community

researchoutreach.org

Partnership enquiries: simon@researchoutreach.org
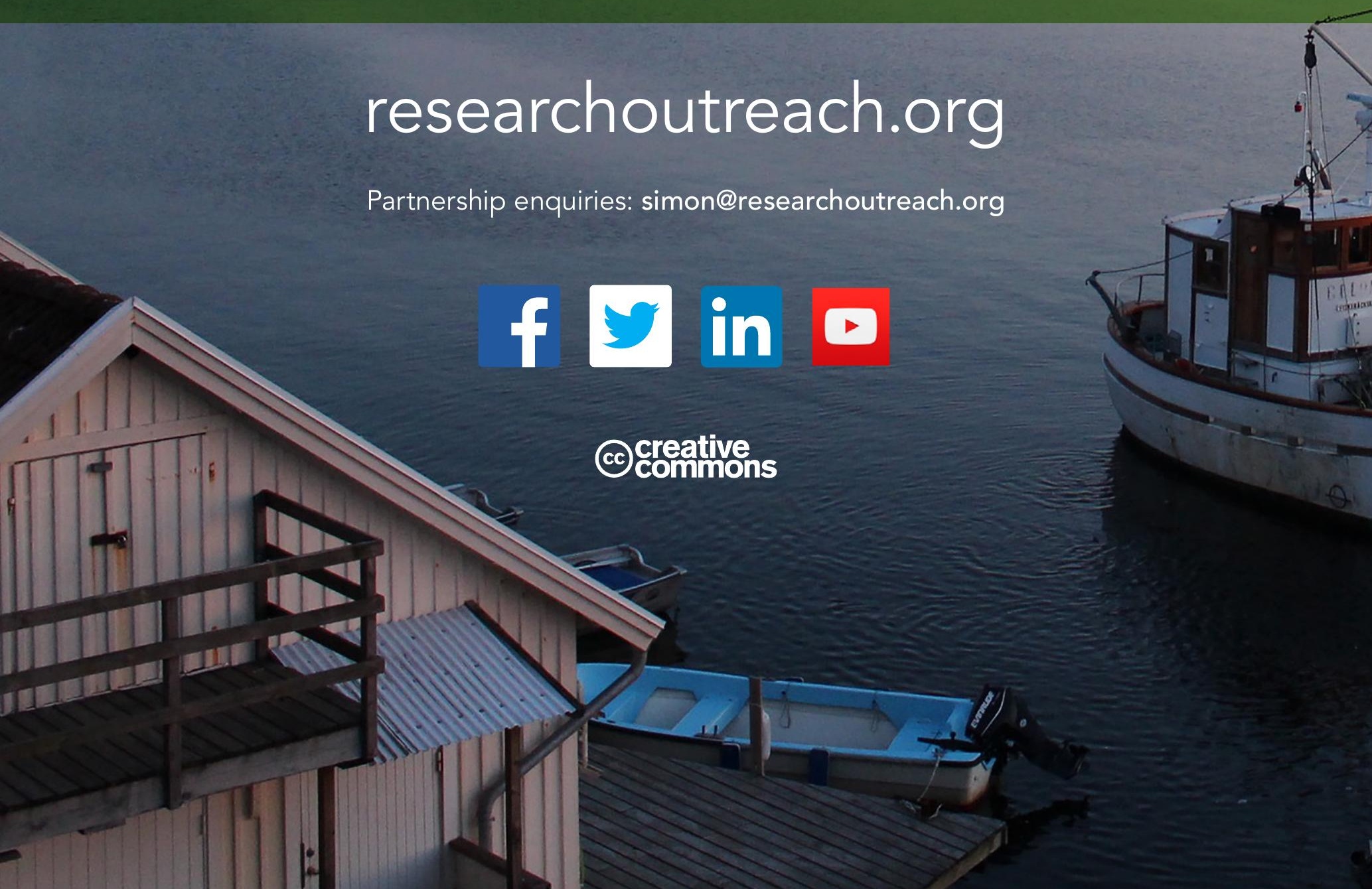